\title{
Resurgence of extracorporeal support for the primary management of cardiogenic shock
}

\author{
Vivek Rao, MD, $\mathrm{PhD}$
}

See related article on pages 333-40.

Cardiogenic shock continues to be a frequent occurrence after acute myocardial infarction, a known complication of acute myocarditis and a somewhat predictable development in patients with end-stage heart disease. Despite several decades of experience, the ideal management strategy for primary cardiogenic shock remains controversial.

The use of intra-aortic balloon pump counterpulsation, first described by Kantrowitz and colleagues in $1968,{ }^{1}$ remains a popular therapy. However, the relatively low-volume displacement $(30-40 \mathrm{~mL})$ and the effect of a compliant vasculature in young patients render this therapy ineffective in most cases except in elderly patients who present with cardiogenic shock secondary to acute myocardial infarction or a complication thereof.

In patients presenting with acute circulatory collapse, intra-aortic balloon pump support is completely inadequate, and the advent of percutaneous extracorporeal life support (ECLS) changed the management of this disease. ${ }^{2}$ However, with greater experience, it became evident that prolonged support with ECLS was associated with poor outcomes. The need for high-circuit anticoagulation and a membrane oxygenator commonly led to thrombocytopenia, bleeding, thromboembolic complications, and eventual death. This led to the introduction of extracorporeal ventricular assist devices that were capable of supporting patients for several weeks if needed. However, many of these devices required central cannulation via a median sternotomy, which proved to be daunting in patients with circulatory arrest or established coagulopathies. ${ }^{3,4}$

In this issue of the Journal, Tarzia and colleagues ${ }^{5}$ report favorable results in a highly selected series of patients from their institution. Over a more than 4-year period, 249 patients received ECLS therapy at their institution. This represents a significant clinical experience with this

\footnotetext{
From the Division of Cardiovascular Surgery, Toronto General Hospital, University of Toronto, Ontario, Canada.

Disclosures: Author has nothing to disclose with regard to commercial support.

Received for publication May 8, 2015; accepted for publication May 8, 2015; available ahead of print June 6, 2015.

Address for reprints: Vivek Rao, MD, PhD, 4N-457, Toronto General Hospital, 200

Elizabeth St, Toronto, Ontario, Canada M5G 2C4 (E-mail: vivek.rao@uhn.on.ca). J Thorac Cardiovasc Surg 2015;150:341-2

$0022-5223 / \$ 36.00$

Copyright (c) 2015 by The American Association for Thoracic Surgery http://dx.doi.org/10.1016/j.jtcvs.2015.05.026
}

technology, and the authors have certainly acquired clinical management expertise. From this cohort, the authors selected 64 patients who presented with primary cardiac etiology shock, excluding postcardiotomy cases. All of these patients received peripheral ECLS with the CARDIOHELP system (Maquet Cardiopulmonary AG, Hirrlingen, Germany), except for 1 patient who required central cannulation. Of note, 27 of these patients presented with an acute deterioration of an underlying chronic pathology.

The newer-generation ECLS circuits, as described in this report, have been proven to be more durable and require less systemic anticoagulation than previous circuits. As such, the clinical outcomes of this therapy have improved considerably, resulting in a shift back to ECLS for the primary management of acute cardiogenic shock. ${ }^{6}$

In the present report, 30-day mortality in the entire cohort was only $20 \%$. However, as with most series, successful weaning from mechanical circulatory support does not always imply a successful outcome, and only 59\% of patients were eventually discharged from the hospital. Not surprisingly, the cohort who presented with an underlying chronic cardiac pathology fared poorly compared with the de novo presentations and displayed no evidence of recovery and higher overall mortality.

What the authors do not describe is their indication for ECLS in this "chronic" cohort. Although most clinicians would agree with their decision to implement peripheral ECLS for patients who present with new acute cardiogenic shock, we and others would still recommend a more durable, implantable ventricular assist device in patients with a known underlying pathology. Indeed, 14 of these 27 patients eventually received an implantable left ventricular assist device (LVAD), and the rationale for not proceeding directly to an LVAD is not entirely clear. When faced with impending end-organ failure, many surgeons may use ECLS to "optimize" a patient for an eventual LVAD implant (a bridge-to-bridge strategy). However, if possible, one would usually proceed directly to implantable LVAD support.

Finally, the casual reader must not be disheartened by the seemingly low success rate for this form of therapy. Ten years ago, we were applauding a 30\% survival to discharge. This report, similar to other contemporaneous series, reports a $59 \%$ survival to hospital discharge. All of us 
who have successfully "salvaged" a young 40-year-old patient from near certain death would agree that a $60 \%$ "success" rate is still a worthwhile endeavor. The ease and rapid initiation of peripheral ECLS combined with the improved anticoagulation management once again have led to a resurgence of ECLS for the primary management of acute cardiogenic shock.

\section{References}

1. Kantrowitz A, Tjonneland S, Freed PS, Phillips SJ, Butner AN, Sherman JL Jr. Initial clinical experience with intraaortic balloon pumping in cardiogenic shock. JAMA. 1968;203:113-8.
2. Tsuneyoshi H, Rao V. The role of extracorporeal membrane oxygenation (ECMO) therapy in acute heart failure. Int Anesthesiol Clin. 2012;50: 114-22.

3. Rao V, Oz MC. Mechanical circulatory assistance. In: Yang SC, Cameron DE, eds. Current Therapy in Thoracic and Cardiovascular Surgery. Philadelphia, PA: Mosby Inc; 2004:562-7.

4. Lad V, Elhenawy A, Harwood S, Maciver J, Badiwala MV, Vallelonga M, et al. Mechanical circulatory support with the ABIOMED BVS5000: the Toronto General Hospital experience. Can J Cardiol. 2010;26:467-70.

5. Tarzia V, Bortolussi G, Bianco R, Buratto E, Bejko J, Carrozzini M, et al. Extracorporeal life support in cardiogenic shock: impact of acute versus chronic etiology on outcome. J Thorac Cardiovasc Surg. 2015;150:333-40.

6. Takayama H, Truby L, Koekort M, Uriel N, Colombo P, Mancini DM, et al. Clinical outcome of mechanical circulatory support for refractory cardiogenic shock in the current era. J Heart Lung Transplant. 2013;32:106-11. 